\title{
Phenotypical difference of Amyloid Precursor Protein (APP) V717L mutation in Japanese family
}

\author{
Masao Abe ${ }^{1 *}$, Naomi Sonobe ${ }^{1}$, Ryuji Fukuhara ${ }^{1}$, Yoko Mori $^{1}$, Shinichiro Ochi ${ }^{1}$, Teruhisa Matsumoto ${ }^{1}$, Takaaki Mori ${ }^{1,2}$, \\ Satoshi Tanimukai ${ }^{1}$ and Shu-ichi Ueno ${ }^{1}$
}

\begin{abstract}
Background: Alzheimer's disease (AD) is the most common form of dementia. Mutations in genes such as those encoding amyloid precursor protein (APP), presenilin 1 and presenilin 2, are responsible for early-onset familial AD.

Case presentation: In this study, we report a $275341 \mathrm{G}>\mathrm{C}$ (Val717Leu) mutation in the APP gene in a Japanese family with early onset $A D$ by genetic screening. This mutation has previously been detected in European families. In the Japanese family we screened, the age at onset of AD was $47.1 \pm 3.1$ years old ( $n=9$; range, 42-52). The symptoms in the affected members included psychiatric vulnerability and focal signs such as pyramidal signs, epileptic seizures, and myoclonic discharges. An MR imaging study showed relatively mild atrophic changes in the bilateral hippocampus and cerebral cortices in all affected members compared with their clinical presentations.
\end{abstract}

Conclusion: We conclude that the clinical features of Alzheimer's disease can be different even when caused by the same mutation in the APP gene. Further clinical and genetic studies are required to clarify the relationship between phenotypes and genotypes.

\section{Background}

Alzheimer's disease (AD) is the most common type of dementia, with a prevalence of over 26 million worldwide [1]. According to the definition of National Institute of Neurological and Communicative Disorders and Stroke-Alzheimer's Disease and related Disorders Association [2], $\mathrm{AD}$ is diagnosed based on detection of two of the following symptoms: amnesia, aphasia, apraxia and agnosia. Atrophic changes occur in the parietal and temporal cortices, especially the medial temporal lobe including hippocampus. The pathological changes in $\mathrm{AD}$ include amyloid plaques (include amyloid beta protein) and neurofibrillary tangles (including hyperphosphorylated tau protein).

Amyloid plaques consist primarily of amyloid $\beta$ protein (A $\beta)$, which is produced when APP is cleaved by $\beta$ secretase and then cleaved again by $\gamma$-secretase as part of the amyloidogenic pathway. According to the amyloid cascade hypothesis, an imbalance between $A \beta$ production and clearance plays a role in the progression of $\mathrm{AD}$. $\mathrm{A} \beta$

\footnotetext{
* Correspondence: masao-a@m.ehime-u.ac.jp

${ }^{1}$ Department of Neuropsychiatry, Neuroscience, Ehime University Graduate School of Medicine, Shitsukawa, Toon-city, Ehime 791-0295, Japan Full list of author information is available at the end of the article
}

oligomers may directly inhibit hippocampal long-term potentiation and impair synaptic function in addition to the inflammatory and oxidative stress caused by aggregated and deposited $A \beta$ as amyloid plaques. These processes lead to neurotransmitter deficits and the cognitive symptoms associated with disease progression [3,4].

The age of onset of AD is usually after the age of 65 years, but can be earlier if influenced by genetic mutations in familial Alzheimer genes. In early-onset familial $\mathrm{AD}$, mutations in the genes related to the amyloid cascade, amyloid precursor protein (APP), presenilin 1 (PS1), and presenilin 2 (PS2), have been found. There are currently 32 known mutations in APP, 178 in PS1, and 14 in PS2, and these have been identified in 86, 392, and 23 families, respectively. Mutations in these three genes account for less than $1 \%$ of all AD cases [5]. Four different missense mutations (to an isoleucine, phenylalanine, glycine, or leucine) have been reported at codon 717, encoding valine, of the APP gene (for a review, see [6]). The Val717Leu mutation in APP has been reported in European-descendant families. In this study, we report the first Val717Leu APP mutation to be detected in a Japanese family, and describe the clinical signs and symptoms in detail. 


\section{Case presentation}

The proband developed deficits in short-term memory and loss of concentration at the age of 45 . He was a banker with 16 years of education. When admitted to our hospital at the age of 47, the findings of a neurologic examination were normal and his mini-mental state examination (MMSE) score was 20/30. His Raven's colored progressive matrices (RCPM) score was 30/36. Neuropsychological examination demonstrated intellectual decline with impaired memory, but preserved visuoperceptual skills. Brain MRI showed mild generalized cerebral atrophy. His conversation

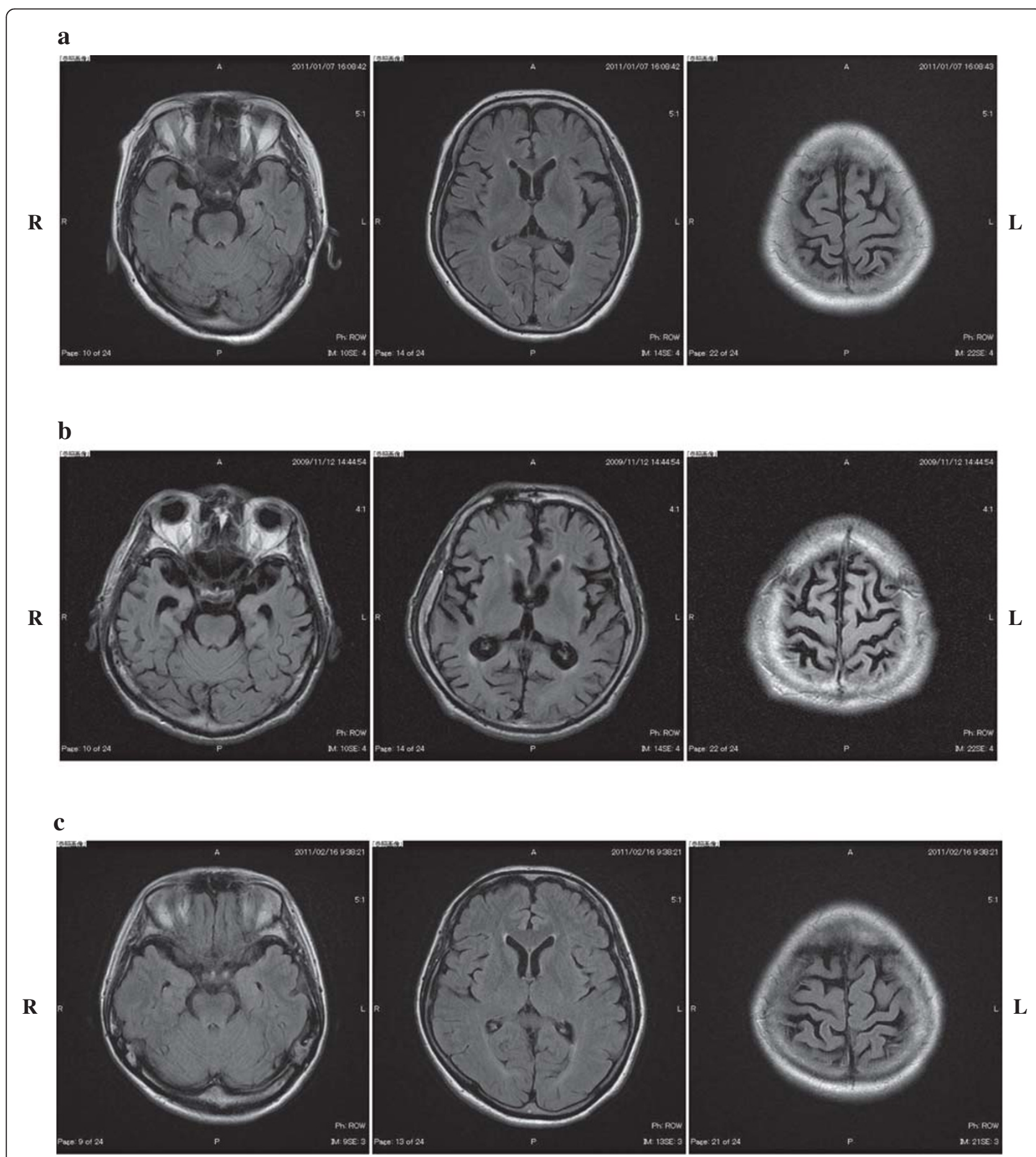

Figure 1 Brain MRI (FLAIR). a) III-9 at the age of 55 years, b) the proband (III-10) at the age of 53 years, c) III-11 at the age of 52 years. All siblings had generalized cerebral atrophy but this was mild relative to their clinical features. 
skills became gradually poorer and he had epileptic seizures several times in a year and developed gait disturbance at the age of 52 . When he was 53 years old (six years after first admission), myoclonus and pyramidal signs were present. Neuropsychological testing could not be carried out at this point. Figures 1a and 2 show brain MRI and ${ }^{123}$ I-IMP SPECT findings, respectively.

\section{Family report}

Figure 3 shows the 3-generation pedigree of a Japanese family with early-onset Alzheimer's disease. The age at onset and death and unusual features are shown in Table 1. We gathered information from medical records of the participants including the proband (patient III-10).

The proband's elder sister (III-9) was a nurse with 14 years of education. She left her job at the age of 40 because she had trouble performing her work as a nurse. She showed clear short-term memory loss at the age of 45 , which gradually worsened. At the age of 55 , she began losing her way home and demonstrating agitation, aggression, irritability, lability, and urinary incontinence. She was admitted to our hospital for further examination. She angered easily, at anything, and needed to stay in a single room for special psychiatric care. Neurologic examination revealed pyramidal signs bilaterally and her MMSE score was $6 / 30$. Brain MRI showed bilateral temporal and parietal atrophy (Figure 1b). She could not live by herself and was re-admitted to another hospital for long-term care.

The proband's younger sister (III-11) was a housewife with 14 years of education. She was married and had a child. She presented to our hospital at the age of 52 years with a 5-year history of gradual progressive memory difficulties. Neurologic examination was normal without any psychiatric symptoms. However, her MMSE score was $24 / 30$ and her RCPM score was 27/36. Brain MRI showed mild bilateral temporal and parietal atrophy (Figure 1c).

\section{Genetic analyses}

Genomic DNA was extracted from peripheral blood leucocytes from five participants (II-8, a non-affected mother; III-7, a cousin; and III-9, 10, 11, the affected siblings) according to a standard protocol, after obtaining written informed consent approved by the Ehime University Ethics Committee. Written informed consent was obtained from the patient for publication of this case report and any accompanying images. A copy of the written consent is available for review by the Editor-in-Chief of this journal.

At first, it was planned to analyze the mutations of known genes causing AD in the proband. Based on the report of Finckh et al. [7], direct sequencing of the PS1 exons 1 to 12 and $A P P$ exons 16 and 17 was done because those mutations account for more than half of family-based autosomal-dominant Alzheimer's dementia. The resulting sequences were compared with those in normal control subjects. Sequencing analysis of the proband (III-10) revealed no mutations in the PS1 gene. The following primers were used for amplification and sequencing of exon 17 of the APP gene: forward, 5' ccaaatgtcccctgcatt $3^{\prime}$ and reverse, $5^{\prime}$ gaaacatgcagtcaagtttacct $3^{\prime}$. The PCR master mix was composed of $12.5 \mu \mathrm{l}$

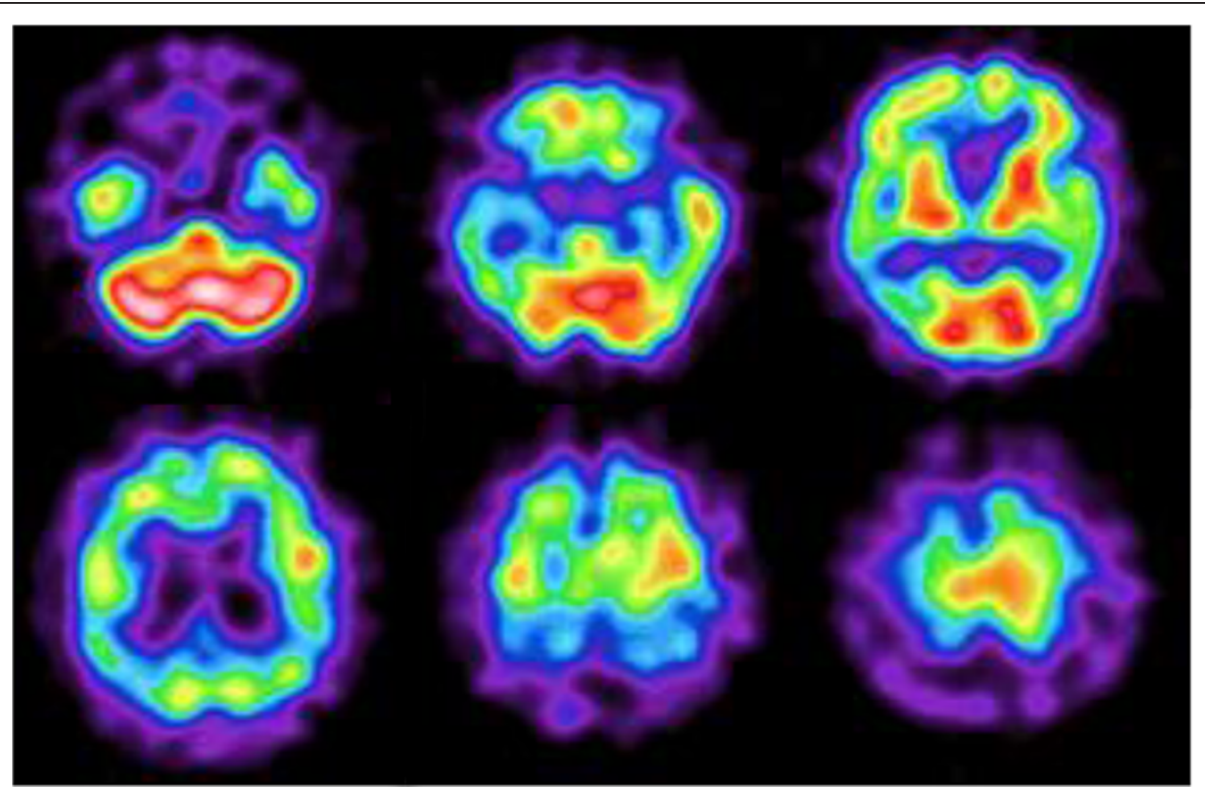

Figure 2 I-IMP SPECT of the proband (III-10) at the age of 53. A generalized decrease drop in cerebral blood flow is shown. 


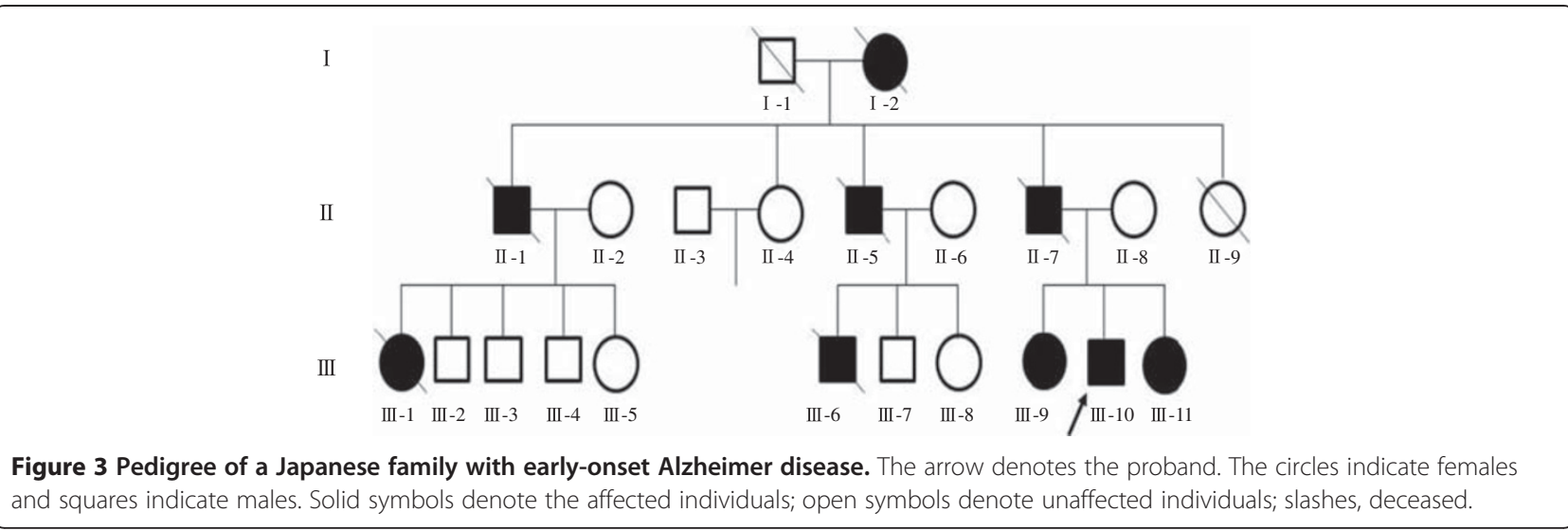

reactions containing $0.5 \mathrm{U}$ of AmpliTaq Gold (Applied Biosystems, Austin, TX), $1.25 \mu \mathrm{l}$ of 10× PCR Buffer, $2.5 \mathrm{nmol}$ of dNTP mixture, $2.5 \mathrm{nmol}$ of each primer and $100 \mathrm{ng}$ of genomic DNA. The conditions for amplification were as follows: an initial denaturing step of $94^{\circ} \mathrm{C}$ for $10 \mathrm{~min}$, followed by 45 cycles of $94^{\circ} \mathrm{C}$ for $30 \mathrm{~s}$, $57^{\circ} \mathrm{C}$ for $30 \mathrm{~s}, 72^{\circ} \mathrm{C}$ for $1 \mathrm{~min}$, and a final elongation step of $72^{\circ} \mathrm{C}$ for $9.5 \mathrm{~min}$. The sequence of exon 17 of the APP gene revealed a single nucleotide substitution in one allele: $275341 \mathrm{G}>\mathrm{C}$ (amino acid: Val717Leu) (Figure 4). The resulting 189-base pair product was assessed by PCR-restriction fragment length polymorphism (PCR-RFLP) analysis using MnlI and run on a 4\% NuSieve 3:1 agarose (Takara Bio, Japan) (Figure 5). This mutation was not observed in 50 normal control subjects (100 normal chromosomes).

\section{Conclusions}

By screening exon 17 of APP and the coding exons of PS1 and PS2, a mutation detection rate of 57\% [7] can be achieved in patients with suspected familial $A D$ (FAD), a figure comparable to those of earlier reports (46-71\%) [8-10]. The family described here was had a

Table 1 Ages of affected members

\begin{tabular}{lccc}
\hline Individual & $\begin{array}{c}\text { Age at onset } \\
\text { (years) }\end{array}$ & $\begin{array}{c}\text { Age at death } \\
\text { (years) }\end{array}$ & $\begin{array}{c}\text { Other } \\
\text { features }\end{array}$ \\
\hline $\mid-2$ & 50 & 65 & not known \\
$\|-1$ & 50 & 58 & not known \\
$\|-5$ & 42 & 56 & not known \\
||$-7$ & 52 & 72 & not known \\
|| $\mid-1$ & 47 & 54 & attempt suicide \\
|| $\mid-6$ & 46 & 48 & depression \\
|| $\mid-9$ & 45 & & disinhibition \\
|| $\mid-10$ & 45 & & seizure \\
|| $\mid-11$ & 47 & & poor insight \\
mean & $47.1 \pm 3.1$ & $58.8 \pm 8.5$ & \\
\hline
\end{tabular}

V717L mutation in exon 17 of APP. This is the first finding of this mutation, which has been reported in several European descendent families [3,11], in an Asian family. In the family, age at onset of $A D$ was $47.1 \pm 3.1$ years (mean \pm S.D.; range, $42-52, \mathrm{n}=9$ ) and age at death was $58.8 \pm 8.5$ years (mean \pm S.D.; range, $48-72, n=6$ ). These findings are different from the data reported by Murrell et al. [3], in which age at onset was $\sim 38$ years (range, 35-39) and age at death was $\sim 46$ years (range, 40-50), but it is similar to data reported by Godbolt et al. [11], in which age at onset and death were $\sim 50$ (range, 48-57) and $\sim 61$ (range, 57-68), respectively. Disease duration was the same, being $\sim 10$ years in all three families. Because ApoE status was shown to affect the age at onset or death and clinical features in the precedent studies, the ApoE status of the family members was analyzed. The ApoE genotypes in III-9, III-10 and III-11 were $€ \times 3 / € x 3, \epsilon x 3 / € x 3$ and $€ \times 3 / € \times 3$, respectively [12]. Thus, it seemed that the ApoE status was not responsible for the features in this family. In this Japanese family, the first symptom was progressive short-term memory impairment, as observed in typical AD. However, there were focal signs and symptoms that were unusual for $\mathrm{AD}$; for example, frontal lobe impairment

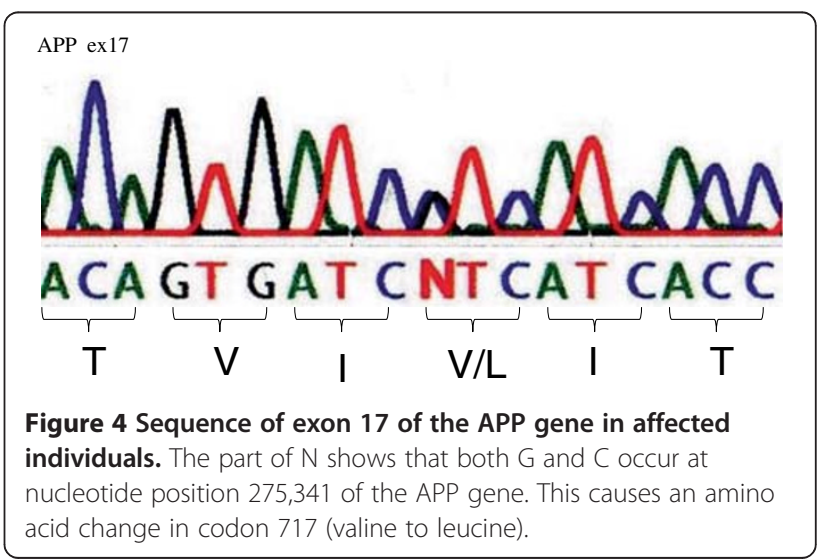




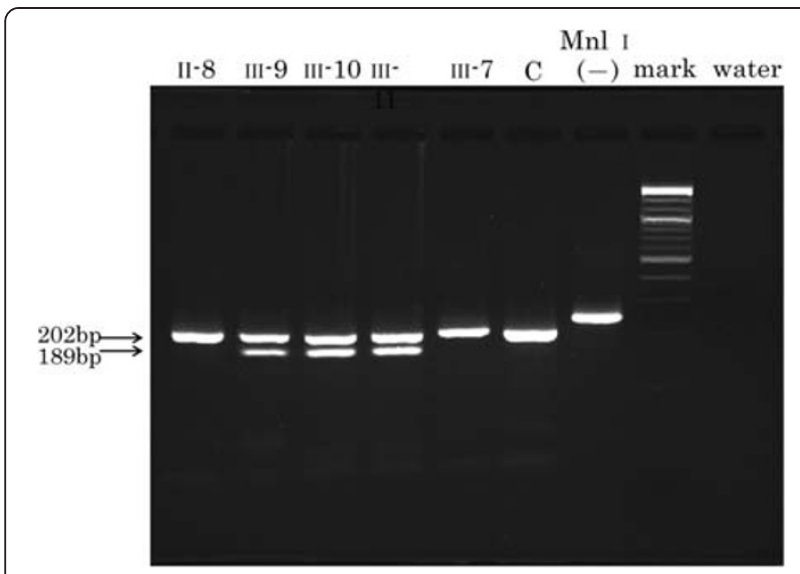

Figure 5 The results of $4 \%$ agarose gel electrophoresis of $\mathrm{Mnl}$ I-digested PCR products. The mutant product is cut into two fragments of 202 and 189 base pairs (bp) by Mnl I digestion after PCR. Individuals III-10 (proband), III-9 and III-11 carry the mutant allele. $\mathrm{C}$ represents a normal control subject.

(depression, apathy, disinhibition) in III-6, III-9 and III10, pyramidal signs in III-9 and III-10, and epileptic seizures and myoclonus in III-10, although there were no focal lesions in either brain MRI or SPECT. Godbolt et al. reported that atypical features, seizures and hallucinations were apparent in several patients with the APP Val717Leu mutation [11]. We suggest that this mutation affects pathways other than the amyloidogenic pathway to modify the features of $\mathrm{AD}$, and that some genes and/ or environments may change the features of $\mathrm{AD}$, even with the same APP mutation.

Further clinical and genetic studies are required to clarify the relationship between phenotypes and genotypes and to identify additional biological factors, such as tau, that may have a role in the pathogenesis of AD.

\section{Competing interests}

The authors declare that they have no competing interests.

\section{Authors' contributions}

MA, YM, SO carried out the molecular genetic studies, participated in the sequence alignment. NS is a treating neurologist of the patient, and made a contribution to acquisition and interpretation of data. MA, NS have been involved in drafting the manuscript, while RF, TM, TM, ST revised it critically for important intellectual content. SU supervised this study, participated in its design and coordination, and revised the manuscript that led to the final approval of the current submission. All authors read and approved the final manuscript.

\section{Acknowledgments}

The authors wish to thank Ms. Mayumi Doi for technical assistance. This work was partially supported by grant from the Ministry of Health, Labour and Welfare of the Japanese Government and the Ehime Graduate University of Medicine's Good Practice fund.

\section{Author details}

'Department of Neuropsychiatry, Neuroscience, Ehime University Graduate School of Medicine, Shitsukawa, Toon-city, Ehime 791-0295, Japan.

${ }^{2}$ Department of Molecular Probes, Molecular Imaging Center, National
Institute of Radiological Sciences, 4-9-1 Anagawa, Inage-ku, Chiba-city, Chiba 263-8555, Japan

Received: 7 November 2011 Accepted: 23 May 2012

Published: 15 June 2012

\section{References}

1. van Es MA, van den Berg LH: Two genome-wide association studies together report three new susceptibility loci for late-onset Alzheimer's disease. CLU, PICALM and CR1 may be involved in amyloid- $\beta$ clearance from the brain. Nat Genet 1047, 41:1047-1048.

2. McKhann G, Drachman D, Folstein M, Katzman R, Price D, Stadlan EM: Clinical diagnosis of Alzheimer's disease: report of the NINCDS-ADRDA Work Group under the auspices of Department of Health and Human Services Task Force on Alzheimer's Disease. Neurology 1984, 34:939-944.

3. Murrell JR, Hake AM, Quaid KA, Farlow MR, Ghetti B: Early-Onset Alzheimer Disease Caused by a New Mutation (V717L) in the Amyloid Precursor Protein Gene. Arch Neurol 2000, 57:885-887.

4. De Jonghe C, Esselens C, Kumar-Singh S, Craessaerts K, Serneels S, Annaert FCW, Van Broeckhoven C, De Strooper B: Pathogenic APP mutations near the $\gamma$-secretase cleavage site differentially affect $A \beta$ secretion and APP C-terminal fragment stability. Hum Mol Genet 2001, 10:1665-1671.

5. Ertekin-Taner N: Genetics of Alzheimer disease in the pre- and postGWAS era. Alzheimer's Research \& Therapy 2010, 2:1-12.

6. Goedert, Spillantini: A Century of Alzheimer's Disease. Science 2006, 314:777.

7. Finckh U, Kuschel C, Anagnostouli M, Patsouris E, Pantes GV, Gatzonis S, Kapaki E, Davaki P, Lamszus K, Stavrou D, Gal A: Novel mutations and repeated findings of mutations in familial Alzheimer disease. Neurogenetics 2005, 6:85-89.

8. Campion D, Dumanchin C, Hannequin D, Dubois B, Belliard S, Puel M, Thomas-Anterion C, Michon A, Martin C, Charbonnier F, Raux G, Camuzat A, Penet C, Mesnage V, Martinez M, Clerget-Darpoux F, Brice A, Frebourg T: Early-onset, autosomal dominant Alzheimer disease: prevalence, genetic heterogeneity and mutation spectrum. Am J Hum Genet 1999, 65:664-670.

9. Finckh U, Muller-Thomsen T, Mann U, Eggers C, Marksteiner J, Meins W, Binetti G, Alberici A, Hock C, Nitsch RM, Gal A: High prevalence of pathogenic mutations in patients with early-onset dementia detected by sequence analyses of four different genes. Am J Hum Genet 2000, 66:110-117.

10. Naruse S, Igarashi S, Kobayashi H, Aoki K, Inuzuka T, Kaneko K, Shimizu T, lihara K, Kojima T, Miyatake T, et al: Missense mutation Val-Ile in exon 17 of amyloid precursor protein gene in Japanese familial Alzheimer's disease. Lancet 1991, 337:978-979.

11. Godbolt AK, Beck JA, Collinge JC, Cipolotti L, Fox NC, Rossor MN: A second family with familial AD and the V717L APP mutation has a later age at onset. Neurology 2006, 66:611-612.

12. Hixson JE, Vernier DT: Restriction isotyping of human apolipoprotein $\mathrm{E}$ by gene amplification and cleavage with Hhal. J Lipid Res 1990, 31:545-548.

doi:10.1186/1471-2377-12-38

Cite this article as: Abe et al:: Phenotypical difference of Amyloid

Precursor Protein (APP) V717L mutation in Japanese family. BMC Neurology 2012 12:38.

\section{Submit your next manuscript to BioMed Central and take full advantage of:}

- Convenient online submission

- Thorough peer review

- No space constraints or color figure charges

- Immediate publication on acceptance

- Inclusion in PubMed, CAS, Scopus and Google Scholar

- Research which is freely available for redistribution 